\title{
Tube-jack Testing for Irregular Masonry Walls: First Studies
}

\author{
RAMOS Luís $\mathrm{F}^{1, \mathrm{a}}$ and SHARAFI Ziba ${ }^{2, b}$ \\ ${ }^{1,2}$ Civil Engineering Department,University of Minho, Guimarães, Portugal \\ aIramos@civil.uminho.pt, ${ }^{\mathrm{b}}$ zibasharafi@gmail.com
}

\begin{abstract}
One of the most well-known non-destructive methods for inspection and diagnosis in historical masonry walls is the flat-jack testing. Although it gives qualitative and valuable results about the local stress level and the deformability of the masonry material, when testing on irregular masonry walls, or walls with larger stone units, experimental and practical problems might occur, leading to inaccurate or useless results. In addition, the testing apparatus is labor, with difficulties in sawing task. Another limitation is the difficulty to test multi-leaves walls. To overturn these problems and to achieve more reliable information, an enhanced type of jacks is proposed in the paper. The new testing system consists of tube-jacks instead of the usual flat-jacks. As part of the preliminary research, analyses with FE models to simulate the differences between the conventional and the enhanced method are presented in the paper. The advantages and disadvantages of both methods are discussed and further research steps are presented.
\end{abstract}

Keywords: Experimental testing, ND Testing, flat-jack testing, masonry

\section{Introduction}

To preserve the historical monuments the use of flat-jack testing is known as a relatively nondestructive technique (ASTM C 1196-04 2004 and ASTM C 1197-04 2004) among the various types of tests in the field of inspection and diagnosis. The primary goal of conducting a flat-jack test is to determine the existing compressive stress; thus, it is performed on the piers and walls. For the historical monuments, the stone masonry walls are usually built irregularly which in turn, makes it difficult to carry out an ideally non-destructive flat-jack test. In response to the shortcomings of this testing method and to expand its capabilities, the tube-jack system is suggested here. The tube-jack is similar to flat-jack in its functionality, but it differs in equipment, where the flat plate of the existing system is replaced with desired number of hoses. The utilization of tubes on irregular masonry walls eliminates the need to create straight slots which may cause partial damage to the construction material.

\section{Flat-Jack Testing}

Flat-Jack testing, as an in-situ test, is carried out to determine such mechanical properties as local compressive stress and deformability of the construction material of masonry buildings. There are two types of flat-jack testing: (a) single flat-jack and (b) double flat-jack method. The information regarding specific usage and assumptions related to each type of test is described in references ASTM C 1196-04 (2004), ASTM C 1197-04 (2004), RILEM MDT.D.4 (2004), RILEM MDT.D.5 (2004), Gregorczyk and Lourenço (2000), and Sharafi (2009).

Amongst all experiments carried out on historical constructions in the area of inspection and diagnosis, flat-jack testing leaves the least damage on the tested case; this can be referred as the most important advantage of this testing method. Also, by employing a flat-jack testing, it is possible to obtain those mechanical properties of a historical building which are practically helpful to come to a suitable conservation design or even strengthening plan when necessary. The required devices are easy to move and use and it is possible to get the results at the same time when the test is being carried out.

There are some disadvantages to flat-jack testing which are important to note. Flat-jack testing is expected to be a relatively non-destructive testing method performed on masonry constructions but 
there is a contradiction between irregularly built masonry walls and flat-jacks as the main tool in conducting the experiment. Many of the masonry buildings, including their walls, were built of stone pieces and because of their random shapes, the stone walls were built irregularly. So, during a flat-jack test on a historical, irregular stone wall, a number of construction material units may also be subjected to unwanted partial damage. In addition, the utilization of electric saw is cumbersome, and at times multiple usage of the saw is required to attain suitable opening to install the jack.

\section{Tube-Jack Testing}

Brief Description Tube-Jack testing is the suggested, enhanced experiment method to replace the existing flat-jack test. In conducting the new testing method, the existing rules and regulations recommended by (ASTM C 1196-04, 2004; ASTM C 1197-04, 2004; RILEM MDT.D.4, 2004; and RILEM MDT.D.5, 2004) are followed, with the exception that the flat-jacks, as the main testing devices, which are replaced by a pre-determined number of hose-jacks. To drill the holes, one can simply follow the path of the joints and make the desired holes in proper spots, regardless of straightness of the path. The hose-jack system avails the freedom to follow the joints' path and removes the need to make holes in inappropriate spots, which reduces the possibility of harming the stone. Additionally, when performing a tube-jack test, the existing correction factors are necessary to obtain the actual compressive stress inside the hoses, as required by flat-jack testing. Eq. 1 depicts the formula used to calculate this stress $\left(\sigma_{m}\right)$.

$\sigma_{m}=K_{m} K_{a} p$

where, $0<K_{m} \leq 1$ is the jack correction factor (also known as calibration factor), $0<K_{a} \leq 1$ is the area correction factor, and $p$ (psi or $\mathrm{MPa}$ ) is the jack pressure required to recreate the original opening as marked by the reference points, within the allowed tolerance. The jack factor is provided by the manufacturer. If the tubes are flexible, the factor will be equal to 1 . The area correction factor must be calculated by the operator.

For the case of computing the area correction factor for the tube-jack tests, if the length of the tubes is assumed as a constant value to all the hoses, its value can be omitted. Experiments has shown that this factor can be given by:

$K_{a} \approx n(2 \pi r) / L$

where, $n$ is the number of the holes, $r$ is the radius of each hole and $L$ in the total length of the distributed holes. For example, the test shown in Fig. 1 with ten tubes located $100 \mathrm{~mm}$ apart and a radius of $10 \mathrm{~mm}$ will lead to an area correction factor equal to 0.71 .

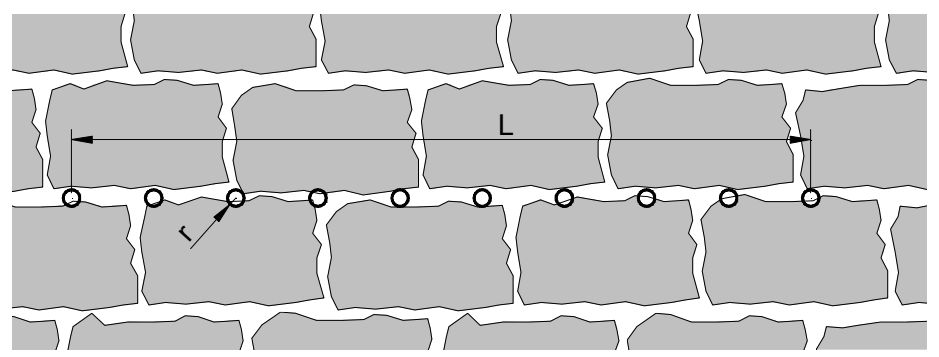

Figure 1: holes on a sample wall for a tube-jack test

During the test procedure, even though some deformation occurs after the drilling; nevertheless, the flexibility of the hose bears the deformed shape of the cross section of the hole. After drilling the specified number of holes, tubes are inserted into the holes, and hydraulic oil is pumped into the tubes. The local compressive stress will be determined using Eq. 1.

Potential Advantages The tube-jack system is mainly suggested to overcome the problems faced when an irregular masonry wall is tested by ordinary flat-jacks. Utilizing the tube-jack system 
eliminates the need for presence of straight joints on the wall. The hoses simply go through the joints and thus reduce the possibility of damaging the wall, see Fig. 2.

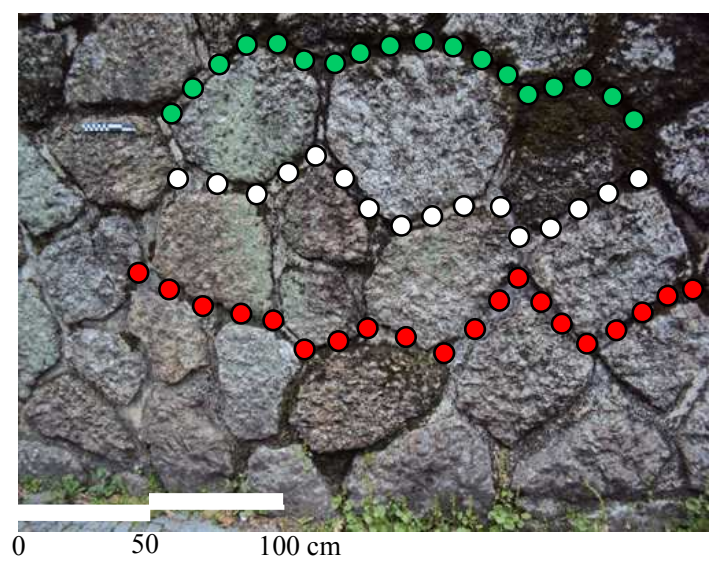

\section{Figure 2: general configuration of tube-jack testing}

Fig. 2 also shows in setting up a tube-jack test, the operator easily has more choices to locate the jacks to perform the test. At times, a straight joint on an irregular masonry wall may not exist to carry out a flat-jack test without harming the main construction material. In other words, tube-jack testing is closer to a non-destructive state than the existing flat-jack method. Furthermore, it is recommended that the test to be conducted as soon as possible after formation of the slot: the time taken for load application shall be approximately equal to the time elapsed since formation of the slot to minimize the effects of creep deformations (ASTM C 1196-04 2004). Inserting a tube immediately after removing any amount of mortar, fills the hollow space without any time gap. This is in direct contrast with performing a flat-jack test, where the process might face unexpected problems and unforeseen delays. Replacing the flat-jack with the tubes allows greater control, improved test processing time, and overall easier testing capabilities.

Potential Disadvantages There are also some disadvantages to the suggested system. Replacing flat-jacks with tube-jacks only facilitate conducting tests on single-layer, irregular walls; whereas, nearly all historical buildings contain many multi-layer walls. In multi-leaf walls, the bed joints of different layers usually do not align. In performing a tube-jack test, the jack needs to penetrate horizontally through the entire thickness of the wall in order to prevent the introduction of any lateral pressure to the wall.

In other words, the suggested system is just an initial step to improve the existing testing method. Further tests need to be performed; various capabilities and shortcomings investigated, and finally, upon satisfactory performance, wide deployment of tube-jack testing could be initiated on historical buildings.

\section{Numerical Simulations}

In order to do more theoretical investigations, some numerical simulations were carried out. The modeling was performed on a sample wall and it consisted of both single and double flat and tube jack testing. Test results for single flat-jack and single tube-jack, double flat-jack and double tubejack were gathered, organized, and compared. The diameter for the holes created to insert the tubes was equal to the width of the slot for the normal flat-jack testing. The first step of each analysis was conducted in linear mode; and the construction material selected was a type of isotropic masonry with a mass density of $2000 \mathrm{~kg} / \mathrm{m}^{3}$; Young modulus of $1500 \mathrm{MPa}$; and Poison ratio of 0.2 . Furthermore, a uniformly distributed load equal to $0.4 \mathrm{MPa}$ was also used on the top of the wall. The wall was simply supported at its lower edge, and it was assumed to be standing free at its left, right and upper edges. According to DIANA (DIANA, 2009), plane stress element type was chosen to model the wall. Each method- whether existing or suggested- was simulated in three phases: 
(1) before creating any change on the tested wall, (2) after opening the slot or the holes, and (3) after introducing the pressure into the jacks.

Single Jack Testing Diagrams and graphs below depict the results of the numerical simulations for single flat-jack testing (Figs. $3 a$ and $3 b$ ), and single tube-jack test (Fig. 3c and 3d) during the second phase of the analyses. Fig. 3a shows the effect of creating the slot on the stress distribution during a single flat-jack test. The enormous stress concentration is easily notable at the corners of the slot (points A and B), and decreases drastically in a distance of about $150 \mathrm{~mm}$ (points C and D). This fact is also shown in Fig. 3b. In contrast, Fig. 3c shows that only a minute stress was created when the same test was performed using a tube-jack. This stress reduces to the lower stress existing in the overall area of the wall, in few millimeters. Fig. $3 \mathrm{~d}$ also presents the same finding.

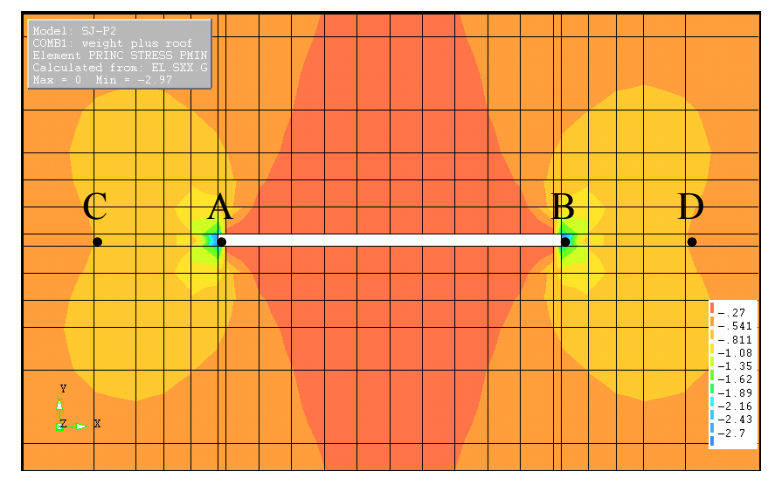

3a)

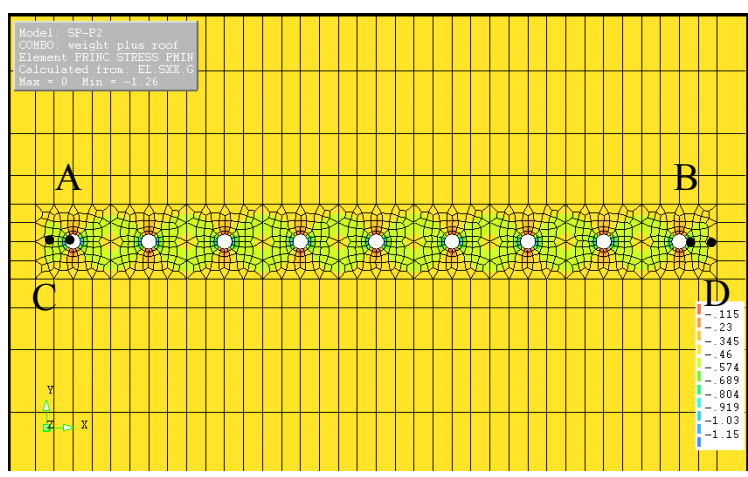

3c)

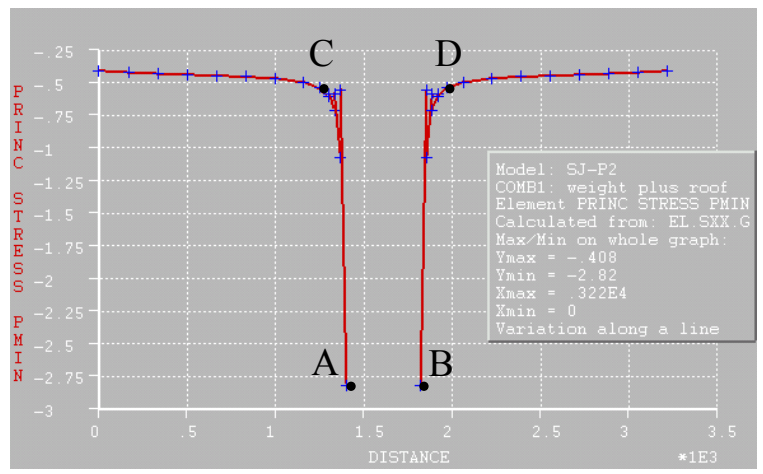

3b)

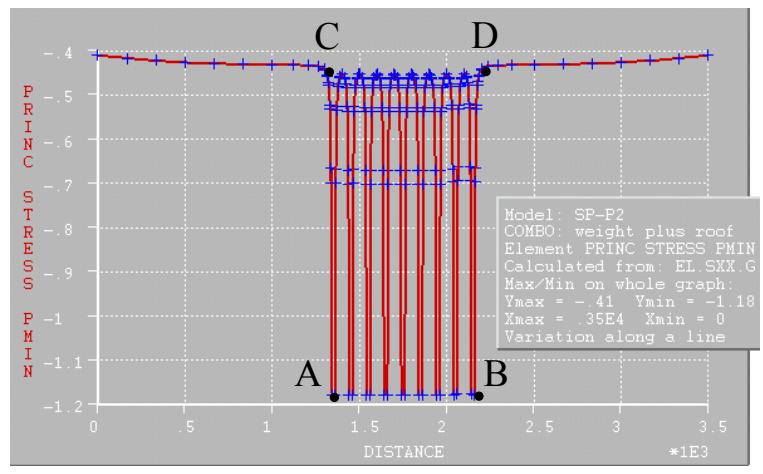

$3 d)$

Figure 3: Comparing the rate of stress change around the jack openings after a normal single flatjack modeling ( $3 a$ and $3 b)$, and the suggested single tube-jack simulation ( $3 c$ and $3 d$ )

In addition to providing more even stress distribution, the tube-jack testing also renders reliable outcome when the existing compressive local stress $\left(\sigma_{\mathrm{m}}\right)$ is calculated. Five pairs of reference points were chosen for the single flat-jack test and nine pairs for the single tube-jack testing. The existing stress $\left(\sigma_{\mathrm{m}}\right)$ was calculated for both models and the results were as expected. The determined stresses from the flat-jack and the tube-jack models were equal to $0.3965 \mathrm{MPa}$ and $0.38 \mathrm{MPa}$, respectively; where the real stress would be equal to $0.40 \mathrm{MPa}$. In this step, the minor differences between the results and the reality are reasonable and will decrease when the tests are modelled with higher accuracy.

Double Jack Testing The results of the analyses of a double flat-jack test and a double tube-jack test are shown in Fig. 4. Similar to Fig. 3, this figure presents different stress distributions depending on the system of testing. Fig. 4a relates to the sudden stress changes around both slots in a double flat-jack test. These sudden changes are similar to the sudden change observed while conducting the single flat-jack test. This occurrence is also shown along the upper slot in Fig. $4 \mathrm{~b}$. Replacing the flat-jacks with tube-jacks leads to the same outcomes, which are represented in Fig. $4 \mathrm{c}$ and $4 \mathrm{~d}$, respectively. 

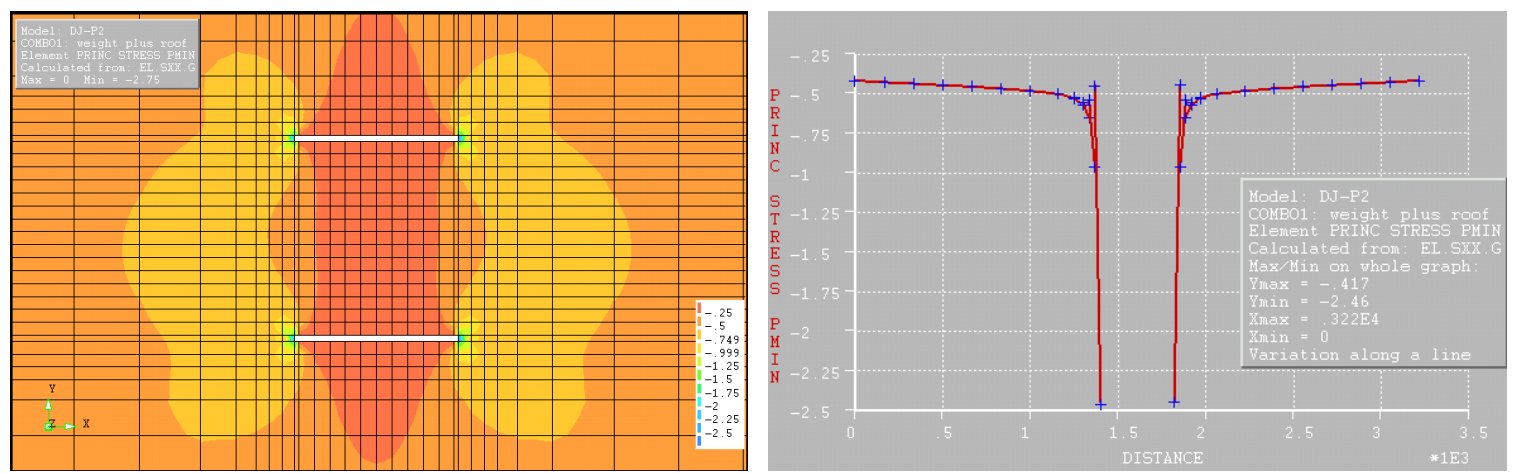

a)

b)
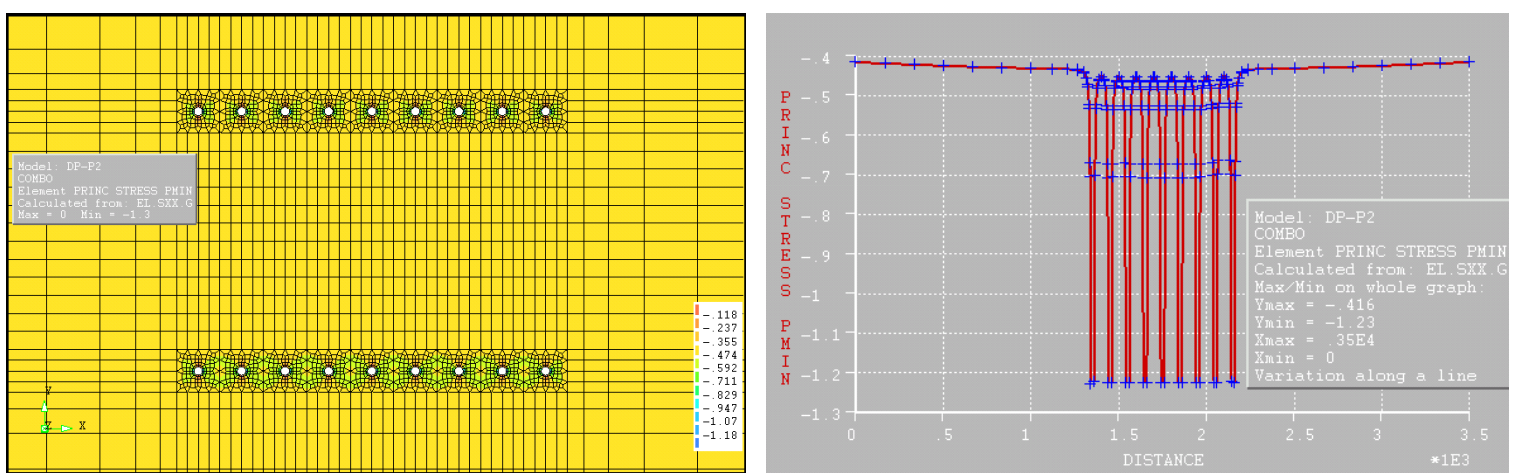

c)

d)

Figure 4: Comparing the rate of stress change around the jack openings after a normal double flatjack modeling ( $4 a$ and $4 b$ ), and the suggested double tube-jack simulation (4c and $4 d$ )

In practice, the main aim of performing a double flat-jack test is (a) to obtain the Young modulus and (b) to determine the deformability of the masonry used. The attained value of Young modulus from analyzing a double flat-jack test was almost the same as selected for the test and acceptable, but the same parameter resulted from a double tube-jack test was far from reality because of the very small displacements of the reference points. This error can be resolved with additional studies or changes in the modeling. Further analyses may include changes in dimension of the tubes, the distance between each two of them or even their quantity.

\section{Conclusions}

This research was set out to introduce an improved system to perform a least-destructive test on existing masonry constructions. First steps of studies about the tube-jack system show that the proposed technique will be a successful substitute for flat-jack testing. The analytical achieved value for the existing compressive local stress was almost the same as the real value. Performing minor modifications in the model of the double jack test should provide acceptable result for Young modulus. In addition, the new system causes less sudden changes in stress distribution around the openings. Last but not least, tube-jack testing leaves less damage on the tested area which is the most desirable advantage of this system.

Investigations should continue with modeling of both the flat and tube-jack testing under nonlinear analysis which may reveal more precise and realistic results. Also, further investigation utilizing the tube-jack testing system should include more in depth and different FE models; modeling the irregular shapes of the stones, and bringing the model into 3-D space. Experimental tests with prototypes will also assist to verify the theoretical results. Lastly, other non-destructive tests such as borehole, strain gauges, etc. employed as some complimentary tests may provide valuable assistance in developing the tube-jack system. 


\section{References}

[1] DIANA Finite Element Analysis Program; User's Manual, Release 9.2.

[2] Gregorczyk, P, and, Lourenço, B (2000). "A Review on Flat-Jack Testing, Engenharia Civil UM." Número 9.

[3] RILEM Recommendation MDT.D.4: In-situ stress tests based on the flat-jack, 2004.

[4] RILEM Recommendation MDT.D.5- In-situ stress- strain behavior tests based on the flat-jack, 2004

[5] Sharafi, Z (2008). "Enhanced Flat-Jack Tests for Irregular Masonry Walls." Master's Thesis, Advanced Master of Structural Analysis of Historical Constructions, University of Minho, Portugal, 2008-09.

[6] Standard Test Method for In Situ Compressive Stress within Solid Unit Masonry, Estimated Using Flat-jack Measurements, ASTM Standard C 1196-04, 2004.

[7] Standard Test Method for In Situ Measurement of Masonry Deformability Properties, Using the Flat-jack Method, ASTM Standard C 1197-04, 2004. 